An Introduction to

Engineering Fluid Mechanics 
Other Macmillan Press titles of related interest:

J.M.K.DAKE: Essentials of Engineering Hydrology

J.A.FOX: Hydraulic Analysis of Unsteady Flow in Pipe Networks

A.B.GOODWIN: Fluid Power Systems - Theory, Worked Examples and Problems

L.HUISMAN: Groundwater Recovery

D.M.McDOWELL and B.A.O'CONNOR: Hydraulic Behaviour of Estuaries

L.M.MILNE-THOMSON: Theoretical Hydrodynamics, Fifth Edition

A.M.MUIR WOOD: Coastal Hydraulics

J.PICKFORD: Analysis of Surge

R.H.J.SELLIN: Flow in Channels

J.D.STRINGER: Hydraulic Systems Analysis

A.VERRUIJT: Theory of Groundwater Flow

E.M.WILSON: Engineering Hydrology, Second Edition

M.S.YALIN: Theory of Hydraulic Models 


\title{
An Introduction to \\ Engineering Fluid \\ Mechanics
}

\author{
J. A. FOX
}

Department of Civil Engineering

University of Leeds

SECOND EDITION

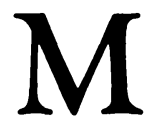




\section{() J. A. Fox 1974, 1977}

Softcover reprint of the hardcover 1st edition 1977 978-0-333-23148-7

All rights reserved. No part of this publication may be reproduced or transmitted, in any form or by any means, without permission

First edition 1974

Second edition 1977

Published by

THE MACMILLAN PRESS LTD

London and Basingstoke

Associated companies in Delhi Dublin

Hong Kong Johannesburg Lagos and Melbourne

New York Singapore and Tokyo

ISBN 978-0-333-23150-0

ISBN 978-1-349-15835-5 (eBook)

DOI 10.1007/978-1-349-15835-5

Typeset by Preface Limited

Salisbury, Wiltshire

This book is sold subject to the standard conditions of the Net Book Agreement

The paperback edition of this book is sold subject to the condition that it shall not, by way of trade or otherwise, be lent, re-sold, hired out, or otherwise circulated without the publisher's prior consent in any form of binding or cover other than that in which it is published and without a similar condition including this condition being imposed on the subsequent purchaser 


\section{Contents}

Preface xi

Principal Symbols xiii

1 Definitions and Hydrostatics 1

1.1 Basic definitions 1

1.2 Viscosity 2

1.3 Non-newtonian fluids 4

1.4 Specific mass, weight and gravity 5

1.5 Pressure at a point in a fluid 6

1.6 Pressure distribution in the atmosphere 7

$\begin{array}{lll}1.7 & \text { Hydrostatic pressures in incompressible fluids } & 8\end{array}$

1.8 Force on an inclined plane lamina 10

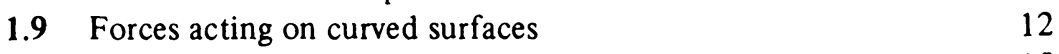

1.10 Surface tension $\quad 15$

$\begin{array}{ll}1.11 \text { Manometry } & 16\end{array}$

2 Hydrodynamics 29

2.1 The continuity equation 29

2.2 The Euler equation 31

2.3 Normal strain and deformation of a fluid element 35

$\begin{array}{ll}2.4 & \text { Rotation of a fluid element } \\ 2.5 & 37\end{array}$

2.5 The Navier-Stokes equations 38

2.6 The velocity potential 39

2.7 The stream function $\quad 40$

2.8 Circulation 43

2.9 Vorticity 44

2.10 The source 46

2.11 The sink 48

2.12 The doublet 51

2.13 The vortex 52

2.14 The uniform wind 53

2.15 Combinations of flow patterns 55

2.16 Pressure distribution around a cylinder in a uniform flow $\quad 59$

2.17 Forces acting on a cylinder 62

2.18 The development of transverse forces 63

2.19 The wake $\quad 68$ 
2.20 Pressure distribution over an aerofoil

2.21 The graphical addition of stream functions and velocity potentials 72

2.22 The flow net

2.23 Percolating flows

3 Dimensional Analysis

3.1 The Buckingham $\pi$ theorems 85

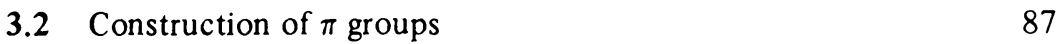

3.3 The physical significance of some commonly used groups 88

$\begin{array}{lll}3.4 & \text { Models } & 90\end{array}$

3.5 Examples of dimensional analysis 95

$\begin{array}{lll}3.6 & \text { Units } & 102\end{array}$

3.7 Dimensional homogeneity of equations 103

4 The Basic Equations of Engineering Fluid Mechanics

$\begin{array}{lll}4.1 & \text { Continuity equation } & 110\end{array}$

$\begin{array}{lll}4.2 & \text { The force equation } & 111\end{array}$

$\begin{array}{ll}\text { 4.3 The energy equation } & 114\end{array}$

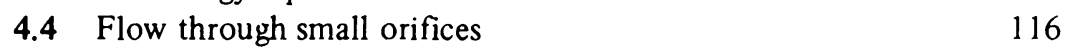

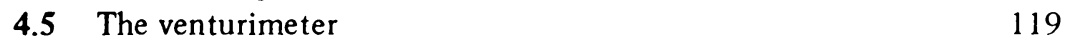

$\begin{array}{lll}4.6 & \text { Notches } & 123\end{array}$

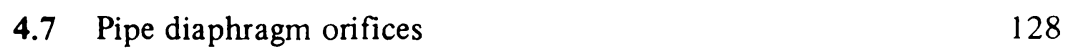

$\begin{array}{ll}4.8 \text { The pitot tube } & 131\end{array}$

4.9 Applications of the force equation 133

4.10 The variation of the Bernoulli constant across stream lines 138

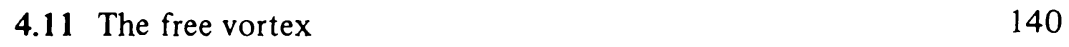

4.12 Radial flow 143

4.13 The free spiral vortex 143

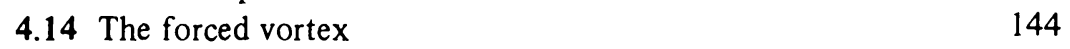

$\begin{array}{ll}\text { 4.15 The Rankine vortex } & 147\end{array}$

$\begin{array}{ll}4.16 \text { Vorticity } & 149\end{array}$

5 Boundary Layer Theory 157

5.1 Formation of boundary layers 157

5.2 The Prandtl mixing-length hypothesis 159

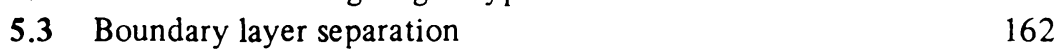

$\begin{array}{lll}5.4 & \text { Drag on spheres } & 167\end{array}$

$\begin{array}{ll}\text { 5.5 Secondary flow } & 168\end{array}$ 
6.1 Simple experiments 176

$\begin{array}{ll}6.2 \text { Laminar flow } & 178\end{array}$

6.3 Turbulent flow 185

$\begin{array}{ll}\text { 6.4 The } f \text { number } & 187\end{array}$

6.5 The Prandtl mixing-length hypothesis applied to pipe flow 193

6.6 The velocity distribution in smooth pipes 193

6.7 The velocity distribution in rough pipes 195

6.8 The universal pipe friction laws 197

6.9 Losses in pipelines other than those due to pipe friction 198

6.10 The energy grade line and the hydraulic grade line 206

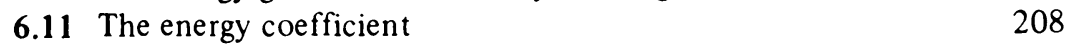

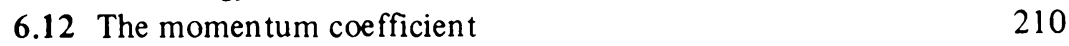

$\begin{array}{ll}\text { 6.13 Flow in pipe networks } & 212\end{array}$

$\begin{array}{ll}6.14 \text { Analysis of pipe networks } & 215\end{array}$

7 Open Channel Hydraulics 230

\begin{tabular}{ll}
7.1 & Uniform flow \\
\hline
\end{tabular}

$\begin{array}{ll}\text { 7.2 Formulae for the Chezy } C & 232\end{array}$

7.3 The Prandtl mixing-length hypothesis applied to uniform free surface flows 234

$\begin{array}{ll}7.4 & 237\end{array}$

$\begin{array}{ll}\text { 7.5 Flow in circular culverts and pipes } & 240\end{array}$

7.6 Gradually varied, non-uniform flow in channels 241

$\begin{array}{ll}7.7 & \text { The analysis of gradually varied flow } \\ 7.8 & 242\end{array}$

$\begin{array}{ll}7.8 & \text { The specific force equation } \\ 7.9 & 245\end{array}$

7.9 The specific energy equation 246

$\begin{array}{ll}7.10 \text { Flow profiles } & 249\end{array}$

7.11 The hydraulic jump 253

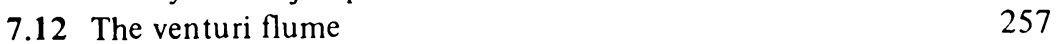

7.13 Broad crested weirs and bed humps 261

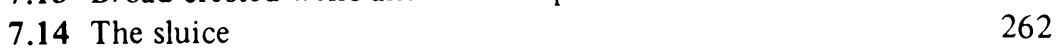

7.15 The prediction of flow profiles in channels 264

7.16 Method of integrating the gradually varied flow differential $\begin{array}{ll}\text { equation } & 268\end{array}$

$\begin{array}{ll}7.17 \text { Surge waves in channels } & 270\end{array}$

8 Pressure Transients 283

8.1 Rigid pipe theory of waterhammer 283

8.2 Sudden valve opening at the end of a pipeline 285

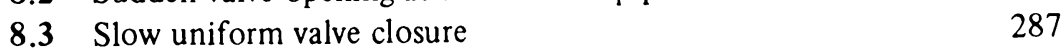


8.4 Elastic pipe theory 291

8.5 Pressure surge caused by instantaneous valve closure 297

8.6 The differential equations of waterhammer 304

8.7 Analysis of pressure transients phenomena, including pipe friction $\quad 313$

8.8 Modification of the techniques to allow for pipe friction 323

8.9 Complex pipelines 326

9 Surge Tanks 338

9.1 The frictionless analysis 341

9.2 The frictional analysis 343

9.3 Complex surge tanks 34.47

9.4 Surge tank modelling 348

10 Rotodynamic Machines 355

10.1 Flow through rotating curved passages 355

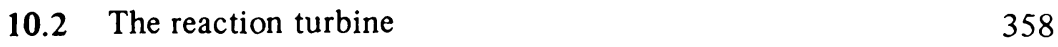

10.3 Impulse turbines 368

$\begin{array}{lll}10.4 & \text { Centrifugal pumps } & 374\end{array}$

10.5 Types of centrifugal pump 378

10.6 The dimensional analysis of rotodynamic machines 385

10.7 Unit speed, quantity and power 385

10.8 The specific speed 388

10.9 Scaling of results from model tests 391

10.10 Cavitation 392

11 Compressible Flow 405

11.1 Introduction 405

11.2 The equation of state 405

11.3 Specific heats 406

$\begin{array}{lll}11.4 & \text { Entropy } & 407\end{array}$

11.5 The velocity of a small pressure wave at sonic velocity 409

11.6 The continuity equation 411

11.7. Conservation of momentum (Newton's second law) 413

11.8 Conservation of energy 415

11.9 Isentropic flow 415

11.10 The convergent nozzle 421

11..11 Flow through a venturimeter 424

11.12 Other types of flow 426

11.13 Isothermal flow in pipelines 427 
11.14 Adiabatic flow in pipelines

11.15 The normal shock

Further Reading

Index 


\section{Preface}

This book is for undergraduates and $\mathrm{HNC} / \mathrm{HND}$ students in both civil and mechanical engineering. The accent throughout has been placed upon the engineering aspects of the subject but it is hoped that the more mathematically minded reader will find sufficient to interest him.

Assumptions upon which analyses are based have been carefully specified. Any analysis is only as accurate as its underlying assumptions and so the reader should develop the habit of assessing the value of a piece of theory by considering the applicability of its assumptions in the context of the problem under examination.

Both engineers and mathematicians have contributed to the study of fluid mechanics and of recent years there has been a marked tendency to use mathematical methods in place of the empiricism that was used in the past. I believe that this trend will continue and academic courses will become progressively more mathematical in their approach.

The systems of units that have been used are the British system, which is still used in many sections of industry and in many parts of the world, and the SI system. Even though the SI system has been introduced in the UK and Europe, it is necessary for British engineers designing projects in those areas to know both systems.

At the end of each chapter questions have been included which it is hoped will be of assistance in understanding the chapter. They are set in both systems of units, the SI values being enclosed in square brackets. Some questions come from examination papers of the University of London, the University of Leeds and the Part II hydraulics examinations of the Institution of Civil Engineers, and I gratefully acknowledge permission to use them; others have been evolved for this book. The answers supplied are of course my own.

The subject is very large and it is not possible to cover every topic in detail. The student will need to read further and a list of suggested reading is included.

I would like to thank Mr J. Higgins, of the Faculty of Applied Science, the University of Leeds, who prepared the drawings.

This second edition has been extended. Chapter 8 now contains material which it is unusual to find in a general textbook of this type. The treatment of waterhammer in this chapter now covers the simpler methods of analysing slowly changing hydraulic controls and indicates how pipe friction can be included in the analysis. The graphical treatment of joints in pipelines is also 
included. An additional chapter on compressible flow has been added for students wishing to study mechanical engineering. This covers most of the material usually presented in mechanical engineering courses.

Leeds, 1977 J.A.F. 


\section{Principal Symbols}

As far as possible all symbols used have been defined in the text as they occur, so any ambiguities arising out of the use of the same symbol to denote different variables can be easily resolved by reference to the text. The dimensions are given in parentheses.

a speed of a gas when expanded down to zero pressure (Chapter 11)

$a$ and $A$ area of flow ( $\left.\mathrm{L}^{2}\right)$

$A$ constant in the pump characteristic equation (Chapter 10) $\left(\mathrm{LT}^{2}\right.$ )

$\alpha \quad$ angle (dimensionless)

constant in the equation that describes the variation of $\mu$ with temperature $\left(\theta^{-1}\right.$,

where $\theta$ is the dimension of temperature)

energy coefficient (dimensionless)

$b$ and $B$ breadth of a channel (L)

surface breadth of a channel (L)

$b \quad$ breadth of a lamina (L)

$B$ constant in the pump characteristic equation (Chapter 10)

$\beta \quad$ the momentum coefficient (dimensionless)

constant in the equation that describes how $\mu$ varies with temperature $\left(\theta^{-2}\right)$

exit angle of a moving blade in a rotadynamic machine (dimensionless)

$c$ or $C$ general constant

c wave velocity (Chapters 6, 8 and 9) $\left(\mathrm{LT}^{-1}\right)$

$c_{\mathrm{p}} \quad$ specific heat of a gas at constant pressure (Chapter 11)

$c_{\mathrm{v}} \quad$ specific heat of a gas at constant volume (Chapter 11)

$C_{\mathrm{d}} \quad$ coefficient of discharge of an orifice, notch or weir (dimensionless)

$C_{\mathrm{D}} \quad$ coefficient of drag (dimensionless)

$C_{\mathrm{v}} \quad$ coefficient of velocity of an orifice (dimensionless)

$C_{\mathrm{c}} \quad$ coefficient of contraction of an orifice (dimensionless)

$C_{1} \quad$ coefficient of lift (dimensionless)

$C \quad$ Chezy constant in free-surface flows $\left(\mathrm{L}^{1 / 2} \mathrm{~T}^{-1}\right)$

constant in the pump equation (Chapter 10) $\left(\mathrm{T}^{2} \mathrm{~L}^{-5}\right)$

d depth of a flow (L)

pipe diameter (L)

$d_{\mathrm{s}} \quad$ height of opening below a sluice gate (Chapter 7) (L)

$d_{c} \quad$ critical depth of a free-surface flow (L)

$\delta \quad$ boundary layer thickness (L)

$\delta^{\prime} \quad$ laminar sublayer thickness (L)

$\delta * \quad$ boundary layer displacement thickness (L)

$\delta \quad$ mean depth of a flow (Chapter 7) (L)

$\delta$ small increment or decrement of a variable

$\Delta \quad$ a finite difference

$E \quad$ specific energy (energy of flow referred to bed of flow) (L)

Young's modulus of the pipe wall material (Chapter 8) $\left(\mathrm{ML}^{-1} \mathrm{~T}^{-2}\right)$

$E_{\mathrm{h}} \quad$ ideal or hydraulic efficiency (dimensionless)

$E_{0} \quad$ overall efficiency (dimensionless)

$E_{\mathrm{m}} \quad$ mechanical efficiency (dimensionless)

$\mathrm{e}^{\mathrm{m}} \quad$ exponential constant (2.71826) (dimensionless)

$\eta \quad$ fractional valve opening (dimensionless)

$F \quad$ fraction of full open valve area

function of (Chapter 8) 


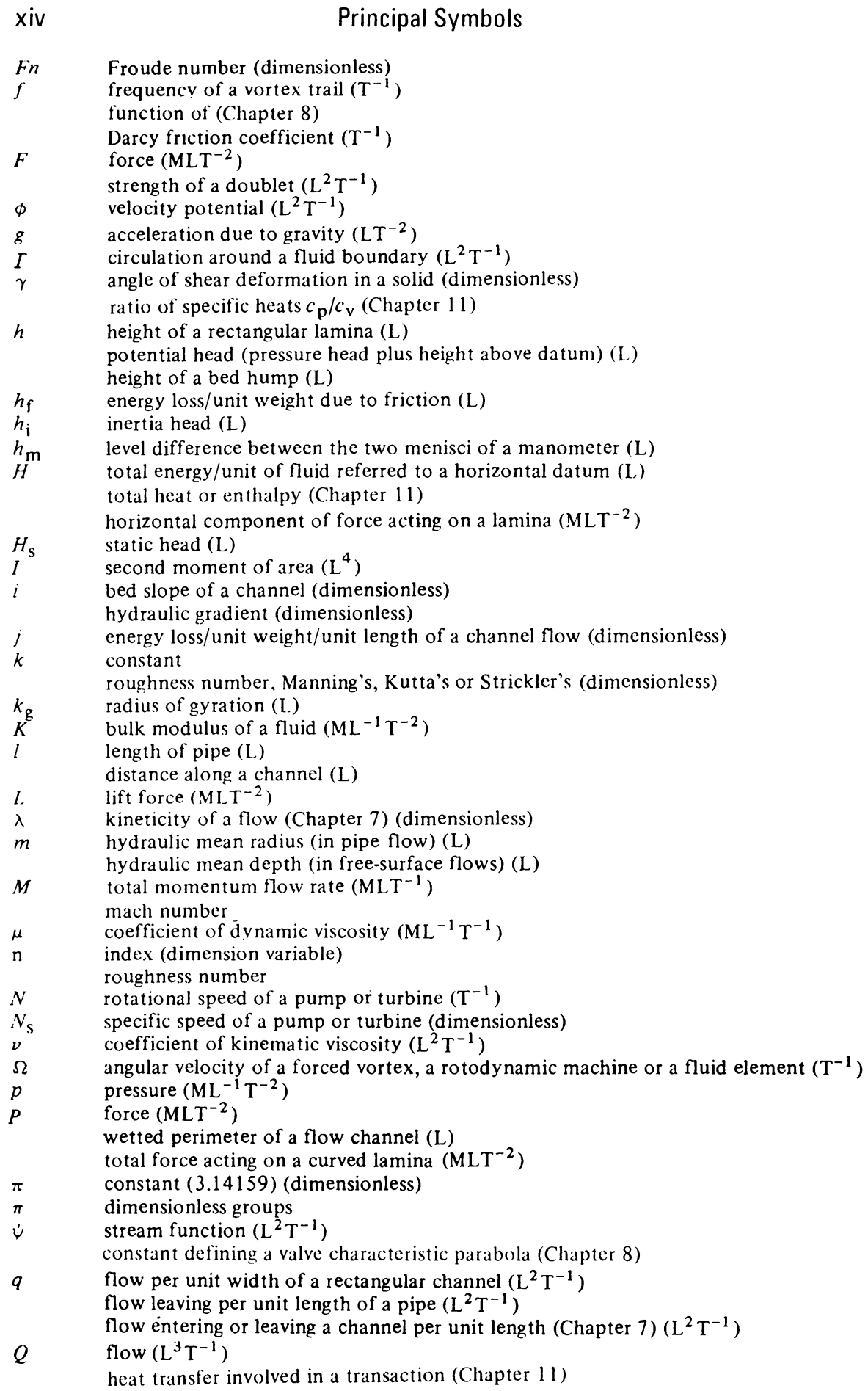




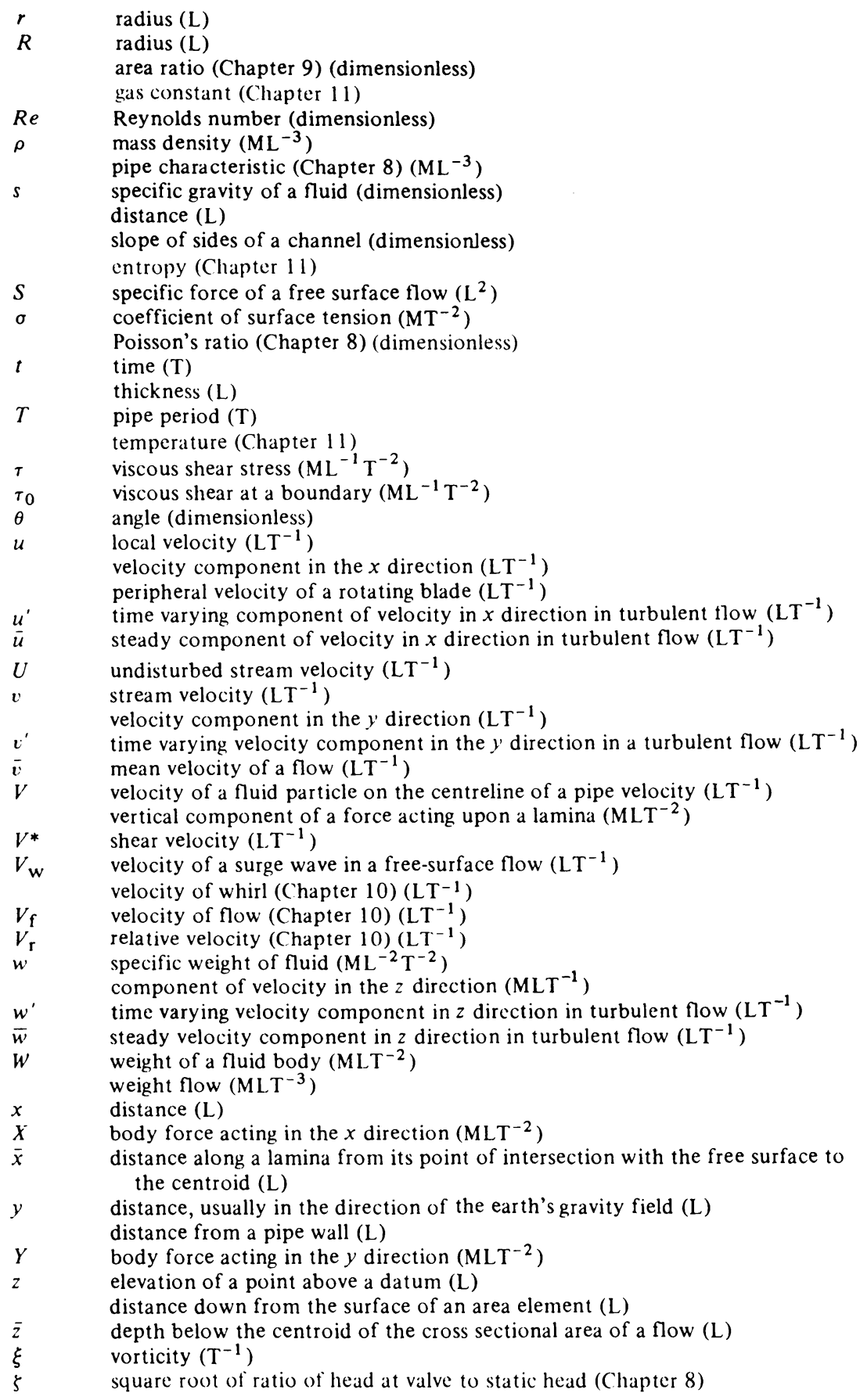

